\title{
Crenças do professorado de Educação Física das escolas públicas de Porto Alegre - RS/Brasil
}

Vicente Molina Neto

\begin{abstract}
Resumo:O presente estudo examinou as crenças docentes de 20 Professores de Educação Física das escolas públicas de ensino básico em Porto Alegre - RS, Brasil. As decisões metodológicas foram de natureza, predominantemente, etnográfica. Realizei observações desses professores no cotidiano das escolas, entrevistas semi-estruturadas e registrei minhas impressões e eventos significativos em um diário de campo. As crenças docentes revelaram-se elementos expressivos da cultura docente dos professores de Educação Física. Elas dão visibilidade ao pensamento dos docentes sobre sua ação na escola, aparecem como estratégias de sobrevivência no ambiente escolar e oferecem aos professores a possibilidade de ampliar sua autonomia relativa no exercício de seu trabalho. Facilitar que os professores de educação física reflitam sobre suas crenças docentes pode contribuir para a discussão de formação profissional.
\end{abstract}

Palavras chaves: Trabalho Docente; Formação Profissional; Trabalho dos Professores de Educação Física.

Este estudo faz parte de uma investigação realizada nas escolas públicas de Porto Alegre - RS, cujo eixo central é a cultura docente do professorado ${ }^{1}$ de educação física. Particularizo a questão nas crenças construídas por esse coletivo docente. É um

\footnotetext{
* A primeira versão deste texto foi construída em 1996, visando integrar minha tese de doutorado "La cultura docente de los profesores de educación física de las escuelas públicas de Porto Alegre" apresentada no Departamento de Didáctica y Organización Educativa da Universidade de Barcelona/Espanha.

** Professor Titular da Escola de Educação Física da Universidade Federal do Rio Grande do Sul/BRASIL.

1 Consciente de que a linguagem é uma construção histórica e social, que reproduzproduz as relações de gênero e de poder em nossa sociedade, ao referir-me ao coletivo docente especificamente tratado neste trabalho, procurei utilizar os termos genéricos professorado de educação física, como forma de reconhecer a simetria entre mulheres e homens na construção inacabada dessa disciplina no contexto escolar.
}

Movimento, Porto Alegre, v. 9, n. 1, p. 145-169, janeiro/abril de 2003 
trabalho qualitativo e a metodologia é predominantemente de natureza etnográfica, do qual participaram vinte professores que atuam nas escolas de ensino básico.

A atividade do dia-a-dia do professorado de educação física, nas escolas públicas, não é uma atividade solitária e asséptica. Está imersa em um mundo de relações e de interações que se estabelecem entre as diferentes parcelas da comunidade escolar. Nesse sentido, o professorado de educação física ajusta seus procedimentos e projeta representações, crenças, pensamentos e sua atividade material - sua cultura docente." Para compreender as crenças desse coletivo docente fiz observações no cotidiano das escolas, entrevistas semi-estruturadas com os professores e adotei um diário de campo para registrar minhas impressões durante minha estada junto aos professores. As entrevistas foram gravadas e transcritas com a autorização dos participantes. O conteúdo das transcrições foi revisado pelos professores, e após isso cada um deles autorizou sua divulgação e a utilização desse material para fins de argumentação e publicação de trabalhos científicos. Com esse procedimento também obtive o primeiro nível de validez das informações coletadas.

A compreensão das crenças docentes adquire grande relevância, tanto para adequar o currículo da formação inicial de professores de educação física às necessidades educacionais dos estudantes que acodem às escolas de ensino básico, quanto para propor políticas públicas de formação permanente, em sua maioria projetadas sem levar em consideração o que pensam, o que acreditam e o que desejam esses docentes. Políticas que, no contexto brasileiro, com freqüência, são planejadas e executadas por especialistas.

O destaque sobre as crenças docentes contempla minha intenção constante de compreender, de modo amplo e em profundidade, a cultura particular do professorado de educação física,

2 Para que o leitor possa inferir sobre a representatividade e legitimidade das declarações dos participantes, apresento seus nomes (alterados para garantir o sigilo das fontes) seguido do tempo de experiência no ensino público: Alberto (31 anos); Ana (18 anos); Carmem (15 anos) Felipe (25 anos); Fernando (1 ano); Francisco (23 anos); Glória (23 anos); Gustavo (24 anos), Helena (23 anos); João (20 anos); Jorge (14 anos); José (21 anos); Marina (1 ano); Monserat (16 anos); Nuria (6 anos), Paula (17 anos) Pilar (8 anos); Rosa (12 anos); Silvia (12 anos); Xavier (15 anos).

3 Os termos cultura docente estão associados aos termos cultura profissional, mais utilizado na consecução das aspirações que os diferentes coletivos docentes mantêm para ver seu trabalho e sua profissionalidade reconhecidos dentro dos parâmetros e critérios socialmente aceitos e historicamente construídos.

Movimento, Porto Alegre, v. 9, n. 1, p. 145-169, janeiro/abril de 2003 
seu lugar na escola, seu desenvolvimento docente, seu vir a ser, ${ }^{4}$ e as interações que se concretizam no seu fazer cotidiano, num contexto específico e singular: as escolas públicas do sul do Brasil. Assim, procurei responder questões do tipo: De que modo as crenças dos docentes intervêm na configuração de sua cultura docente nas escolas públicas de Porto Alegre, e de que modo essas crenças se articulam e se entrelaçam com outros de seus elementos constitutivos?

Inicialmente, sublinho a necessidade de entender a relação entre o pensamento do professorado de educação física e sua atuação docente nas escolas. Segundo Clark y Peterson (1990), é evidente dizer que o que os professores fazem é conseqüência do que pensam (p. 445).

Entendo que o pensamento é resultado da atividade material do sujeito, que conhece e que se comunica. Assim sendo, em relação ao pensamento do professor, há que se admitir como evidente a seguinte antítese dialética: o que os docentes pensam e crêem está fortemente influenciado pelo que fazem nas escolas.

Portanto, a relação dialética que acabo de explicitar demanda ir além das considerações que estabelecem o pensamento do professorado de educação física em termos exclusivos da sua atividade mental interior. Ela aponta para o estudo de seus aspectos exteriores. Inspirado em Geertz (1994, 1996) pergunto: Que elementos interferem na configuração de seus processos mentais? De que modo o contexto age sobre o pensamento de um coletivo específico, nas representações que faz da realidade e o sentido que lhes dá? São questões que sinalizam um processo com características ideológicas.

Existe um volume considerável de investigações sobre o pensamento do professorado, sejam relacionadas à sua atividade cognitiva (produção de conhecimento), tratando o pensamento em relação à eficácia docente nas atividades de ensino, ou à formação de professores. Essas investigações parecem coincidir

4 A idéia de vir a sertomo por empréstimo de Freire $(1979,1992)$, que significa ser mais, isto é, homens e mulheres inconclusos, em seu processo de conscientização crítica sobre o mundo e em busca permanente da libertação das relações de dominação a que estão submetidos.

5 De acordo com Severino (1986), entende-se por ideologia um sistema de crenças que resulta do processo de interação da atividade da consciência do indivíduo com os determinantes socioculturais da realidade social. Em determinada perspectiva explica e justifica a realidade, em outra dissimula e oculta as verdadeiras condições da vida social.

Movimento, Porto Alegre, v. 9, n. 1, p. 145-169, janeiro/abril de 2003 
com a idéia de que o pensamento dos professores consiste num sistema articulado de crenças, conhecimentos e valores. Cito três trabalhos, que me dão referência para dialogar com as informações do trabalho de campo: a resenha de Clark y Peterson (1990), o estudo de Calderhead (1988) e o de Contreras Domingo (1985).

Clark e Peterson (1990) revisam as investigações sobre o pensamento do professorado, tanto em relação às principais atividades de ensino que o professor leva a termo (planejamento do ensino, interação com os alunos, pressupostos teóricos, crenças), quanto seus efeitos observáveis na sua atuação em aula e os gerados sobre a atividade do aluno. Os autores tentam mostrar que o pensamento do professorado se desenvolve através de estímulos específicos de cada atividade de ensino. Nessa perspectiva, o professorado desenvolve formas diferentes de pensar nos momentos de planejamento, na interação com os alunos e na atividade que provém das suas experiências e relações com o entorno ecológico em que se desenvolve sua atividade docente. Considero explicativa essa forma de compreender o pensamento do professorado, mas sua leitura merece atenção, pois pode pressupor que o pensamento do professorado é algo mecânico, além de fragmentar o conhecimento sobre a atividade docente. Mesmo assim, seleciono, para a argumentação deste estudo, uma das categorias do pensamento do professorado, proposta por Clark e Peterson (1990, p. 450):

A terceira categoria, as teorias e crenças dos docentes, representa o amplo acervo de conhecimentos que possue eque afeta seu planejamento, os seus pensamentose suas decisões interativas (...) Sem dúvida, os docentes também podem desenvolver teorias e crenças como resultado de sua reflexão durante a interação em aula e de sua planificação prévia e posterior a ela. (p.450)

Destaco que o pensamento não é algo ideal, como uma luz que acende e gera um ser iluminado. Ao contrário, o pensamento é construído na ação e está impregnado por ela (Shön, 1992). O professor pensa porque aprende, porque conhece, porque percebe o mundo na produção de conhecimento.

A revisão de Calderhead (1988) trata o pensamento do professorado como um tipo de conhecimento, pois considera o professor como um ator que constrói sua própria prática, e um sujeito capaz de promover mudanças no ensino. Também considera que o pensamento do professorado se desenvolve unido às decisões que toma na prática. Do texto de Calderhead sublinho a revisão bibliográfica. Segundo esse autor, entre os conceitos

Movimento, Porto Alegre, v. 9, n. 1, p. 145-169, janeiro/abril de 2003 
pelos quais o professorado organiza e dá substância ao seu pensamento estão as redes semânticas, os conceitos prototípicos, os roteiros, as rotinas, os esquemas, os sistemas de constructos, as teorias implícitas, as teorias expostas e as metáforas. O importante a ser destacado é que embora os termos anteriormente apresentados tenham, na literatura, significados diferentes, eles contemplam a idéia de que a atividade cognitiva do docente (e outras atitudes em outros planos) está orientada por um sistema pessoal de crenças, valores e princípios. Esse sistema confere sentido ao pensamento e à atividade do professorado.

De acordo com Munby (1988), as metáforas são as figuras de linguagem e os símbolos que melhor representam e expressam o pensamento e as crenças do professorado. Esse autor considera que as metáforas, além de expressarem o pensamento do professorado, refletem a visão e a construção que o professor faz da realidade, pois estas são articulações de princípios genuínos de ação e crenças mantidas pelos professores. Em outras palavras, as metáforas são os ícones ${ }^{6}$ que expressam as crenças do professorado. ${ }^{7}$ Munby argumenta que o estudo das metáforas é uma forma de ajudar o professorado a conhecer e refletir objetivamente sobre a realidade subjetiva que constroem.

Nessa linha de argumentação está Contreras Domingo (1985). Esse autor revisa os estudos que versam sobre o pensamento do professor e propõe esse ponto como o início de uma ação reflexiva do próprio professor sobre seu próprio pensamento e sobre as inovações educativas, nas quais está envolvido, já que o pensamento do professor é, sobretudo, o estudo de sua forma de conhecer. Na perspectiva desse autor, o estudo do pensamento do professor não é um modelo de formação, mas uma estratégia que serve para estimular o pensamento dos professores, convertendo-se em uma forma de desenvolver o currículo e propor inovações educativas.

Também argumentando sobre o tema, Guerrero Lopéz (1993) considera que as crenças do professorado têm, como características principais:

6 Considero o ícone como um símbolo, uma representação, gráfica ou não, que resume, com originalidade, uma série de pensamentos, um sistema de idéias, conceitos, princípios e relações entre eles e interpretações articuladas sobre um tema específico.

7 É importante lembrar que, freqüentemente, quando nos referimos a alguém, seja de forma positiva ou negativa, fazemos uso de metáforas que ganham sentido no contexto do discurso.

Movimento, Porto Alegre, v. 9, n. 1, p. 145-169, janeiro/abril de 2003 
F uma presunção existencial;

F uma alternância com o meio;

$\mathrm{F}$ aspectos afetivos-valorativos;

F uma lembrança episódica;

F um caráter herdado das crenças de seus professores;

F funcionam como microlentes construtivistas.

Para esse autor, a aula está estruturada de acordo com as crenças do professorado. Os sistemas de crenças determinam a forma como os coletivos docentes organizam sua visão de mundo, além de definir os dilemas e as tarefas educativas. As crenças estão impregnadas de sentimentos, manifestam o estado de ânimo do docente, suas emoções, preconceitos e estão organizados no interior de sua estrutura cognitiva. Para Marcelo Garcia (1987) as crenças docentes estruturam e organizam o mundo profissional do professor, além de reduzir-lhe a necessidade de processar a informação que acumula na sua atividade docente.

As crenças docentes são imagens que o professorado faz de si mesmo, de seu trabalho e dos modelos e sonhos que persegue, e se traduzem em normas e princípios de ação no ensino e fora dele. Essas crenças identificam tipos de professores, diferentes categorias de experiências docentes e, sobretudo, o essencial de sua ação docente. Além disso, distinguem os coletivos docentes de outros grupos, no contexto social e cultural. Têm, também, sua máxima validez identificadora quando estão situadas temporalmente na relação do sujeito histórico com o contexto social. Isto é, o sujeito representa o mundo e gera cenários e modelos mentais de acordo com o que acredita e o que conhece dele. Assim, considero as crenças docentes um tipo de conhecimento impregnado de emoções, preconceitos e valores que o professor constrói - resultado das informações que acessa e das relações que estabelece com seu contexto mais amplo. Creio que as crenças docentes são pensamento em estado tangível. Através delas o professorado encontra seu lugar no coletivo e na cultura. Conforme Marrero Acosta (1992), o tipo de problemas com que trabalha o professor, as experiências que realiza são culturais e é delas que se nutre o pensamento do professorado.

Portanto, essas crenças, essas teorias implícitas, esses modelos mentais ou ícones nos levam a considerar que os pensamentos e crenças do professorado de educação física são, ao mesmo tempo, manifestação e elemento constitutivo de sua cultura docente particular, no marco da escola pública. Ante um

Movimento, Porto Alegre, v. 9, n. 1, p. 145-169, janeiro/abril de 2003 
contexto, muitas vezes adverso ao seu trabalho, dado o caráter intelectualista da escola, o professorado de educação física desenvolve um sistema de crenças ou, nas palavras de Marrero Acosta (1992), um modelo mental que se caracteriza por um processo ideológico repleto de estratégias de sobrevivência (Woods, 1989). Essas crenças permitem a esse grupo enfrentar a relação interativa com a cultura escolar e as contigências de seu trabalho de modo satisfatório e com respostas originais.

\section{As crenças do professorado de educação física: um processo ideológico}

O professorado de educação física, como os demais professores da escola pública, constrói, ainda cedo, um pensamento complexo não-linear. Nele intervêm: a atividade material na escola; o conhecimento específico adquirido nas atividades de formação e o construído no trabalho ordinário; as relações que mantêm com as demais parcelas da comunidade escolar, sua prática reflexiva (Zeichner, 1992) e as ideologias que circulam na escola. Nesse sentido, Zeichner (1985, p.111) afirma que:

Apesar de que predominem determinadas ideologias e práticas, as escolas são

lugares onde se enfrentam ideologias que competem entre si.

Segundo esse autor, o professorado enfrenta essa competição e as pressões que recebe na escola, com resposta, funcionais: a submissão estratégica, a adaptação internalizada e a redefinição estratégica (Lacey, 1977). Woods (1989, p. 31) classifica essas respostas funcionais como compromisso estratégico e estratégias de sobrevivência. Para este autor:

[...] os professores estão submetidos a diversas pressões e obrigações-o currículo dominado pelos exames, a escassez de recursos, oelevadonúmero de alunos em sala de aula, a pouca motivação, a clientela resistente ao seu trabalho, o aumento das responsabilidades e a avaliação dos professores - que não pode escapar devido a seu compromisso pessoal. Onormal é que resolvam os problemas mediante compromisso estratégico e mediante estratégias de sobrevivência. Estas últimas são as que permitem ante a tudo isso o professor sobreviver em seu posto de trabalho, mas necessariamentenão facilitam o ensino; todavia, tal éa necessidade de auto-estima profissional que freqüentemente são interpretadas comoestratégias de ensino.

Assim, considerando as declarações do professorado de educação física que participou deste estudo, seus pensamentos e suas crenças parecem que se caracterizam por uma estratégia de sobrevivência composta por respostas utilitárias e pragmáticas

Movimento, Porto Alegre, v. 9, n. 1, p. 145-169, janeiro/abril de 2003 
às demandas da cultura escolar. Os participantes verbalizaram seu pensamento, articulado-o em torno de quatro crenças básicas, integradas entre si.

F a crença do pouco valor da atividade docente;

F a crença do professor diferente;

F a crença das finalidades educativas distintas;

F a crença de um modelo de professor necessário para a escola pública.

Apresento, na seqüência, o significado dessas crenças na perspectiva dos participantes. Para cada uma delas, procurei identificar em suas falas uma expressão êmica (Aguirre Baztán,1995) que, como um ícone associado, melhor pudesse sintetizar e representar os pensamentos, necessidades e interesses do professorado de educação física nas escolas públicas de Porto Alegre. Interessou-me identificar esses ícones e através deles, compreender quais são as crenças e visões que têm os professores sobre seu próprio trabalho e também que outras crenças delas emergem.

\section{A crença do pouco valor docente Ícone: o sucateamento da escola pública}

A crença no pouco valor docente provém da reação individual e coletiva que o professorado faz às condições e circunstâncias conjunturais a que está submetida a escola pública na sociedade brasileira. ${ }^{8}$ No Brasil, com uma economia politicamente orientada por interesses do mercado internacional que propõe privatizar a maior parte das obrigações do estado de bem-estar, as escolas públicas e o professorado agonizam à espera de políticas públicas que, sobretudo, lhes garantam condições dignas de vida material, circunstâncias favoráveis para executar bem o seu trabalho e cumprir com altivez seu papel social, e o acesso da população à educação de qualidade.

Nas atividades que realiza em conjunto com os demais coletivos docentes, o professorado de educação física importa essa reação para o contexto de sua atividade específica, na escola,

\footnotetext{
8 Reconheço que em algumas cidades brasileiras, como é o caso de Porto Alegre, há um grande esforço dos governos municipais em qualificar a escola de ensino fundamental e médio com condições materiais objetivas adequadas e valorização dos professores, através de projetos de formação permanente e recomposição de sua base salarial.
}

Movimento, Porto Alegre, v. 9, n. 1, p. 145-169, janeiro/abril de 2003 
e lhe dá um formato próprio. Pode-se vislumbrar que a crença no pouco valor docente do professorado de educação física se configura em três aspectos fundamentais: a própria natureza de sua tarefa docente, as condições materiais objetivas de seu trabalho na escola e o descompasso com a política educacional.

A crença de que o trabalho docente é um trabalho pouco valorizado, tanto socialmente quanto economicamente, desde o ponto de vista da natureza específica de sua atividade, mobiliza de forma muito intensa a ação política do professorado de educação física da escola pública. Ela se traduz, no âmbito externo à escola, por sua convergência com as lutas gerais do professorado em geral e da escola pública, mas, no interior da escola, esse coletivo manifesta um pensamento divergente que o move nas relações interativas que mantém com as diferentes parcelas da comunidade escolar. Essa é uma crença que, tanto estimula o coletivo a reagir positivamente no enfrentamento de situações conflituosas e negociar suas posições - situação que utiliza um discurso com conteúdo político-pedagógico -, quanto trava e prejudica seu ímpeto para o trabalho, pois conduz o coletivo à perplexidade ao contemplar o desinteresse e o desconhecimento que a própria comunidade escolar tem por seu trabalho. Segundo a participante Helena,

Muitas pessoas de todos os níveis intelectuais, me perguntam: Se o professorado está tão desgastado por que não muda de atividade profissional? Eles pensam que somos ingênuos. Pergunto: Como vou mudar de atividade agora, se éo que sei fazer, o que eu gosto de fazer, se eu me preparei para isso? Nãoé por acaso que sou professora de educação física. Então agora vou ser vendedora, seja lá o que for, porque tenhoéque ganhar dinheiro. Quandoé uma pessoa sem informação que te faz esse tipo de pergunta, tu pensas: Bom éignorante, passa! Mas quando tu vês um jornalista famoso dizer isso tu fica sem saber o que dizer. Outro dia li no jornal: Se há tantos professores insatisfeitos por que não largam o magistério? Não é tão simples. Não poderia mudar minha atividade de toda a vida.

A precariedade das condições materiais didáticas para a aula de educação física também intervém decisivamente para que se solidifique, no pensamento do professor, a crença do baixo valor docente de sua atividade. Durante o trabalho de campo, observei que, na maioria das escolas, os professores estavam trabalhando com poucos materiais e alguns deles quase que completamente estragados, apesar dos insistentes pedidos de reposição que fazem às direções das escolas. Segundo os professores, não é raro que façam coleta de dinheiro entre os alunos para comprar material novo para suas aulas. Também organizam muitas festividades na escola com o objetivo de arrecadar dinheiro

Movimento, Porto Alegre, v. 9, n. 1, p. 145-169, janeiro/abril de 2003 
junto à comunidade para comprar novos materiais para as aulas de educação física.

O pensamento divergente do professor de educação física se manifesta também em relação a outros professores desse mesmo coletivo, já que nenhum dos participantes se reconheceu individualmente pouco valorizado em sua escola. Em suas referências quanto à desvalorização do professorado de educação física, sempre falaram dos outros, de outras escolas, isto é, em sentido genérico. O professor, individualmente, não se reconhece pouco valorizado na sua escola, mas no discurso genérico, ao tratar do coletivo, sim. O argumento de Pilar é bastante esclarecedor:

O professor de educação física que me antecedeu não queria participar de nada e não queria saber de nada. Quando cheguei na escola, sem saber estava começando um trabalho diferente. Me impus junto aos professores da escola pelo conhecimento que tinha, pois nas reuniões debatia qualquer assunto. Ganhei muito respeito por isso, inclusive da direção. Não me limitava só à educação física. Mesmo quando tivemos uma diretora autoritária eu notava que ela me respeitava, me ouvia pelo conhecimento que eu tinha. Penso que quando lhe convém, o professor se deixa marginalizar. Agora, quando está disposto a trabalhar é diferente. Os próprios alunos percebem a diferença.

A baixa remuneração paga ao professorado é o principal argumento para a crença do baixo reconhecimento social e econômico. Argumento que é potencializado pelas condições materiais objetivas precárias, por circunstâncias adversas para realizar seu trabalho, de poucas oportunidades e incentivos para a formação permanente e de um elevado volume de trabalho. Essa submissão dos professores é definida por Felipe, como tarefa para o Super-Homem:

Para enfrentar essas condiçôes de trabalho adversas o professor precisa participar da sociedade civil organizada, nos sindicatos, nos partidos políticos e etc. Ante a situação que nos encontramos, o professor teria que ser quase um superhomem...porque emnossa sociedade o sucateamento da escola públicaéflagrante.

No âmbito das políticas educativas e das relações interdisciplinares, essa desvalorização é especialmente acentuada. A educação física opera com a pedagogia do corpo e o ensino da cultura corporal no contexto de uma cultura escolar cuja ênfase está no intelectual. Então como o projeto social brasileiro é, prioritariamente, um projeto centrado no desenvolvimento econômico, é fácil supor que a escola e a comunidade valorizem mais aquelas disciplinas e atividades escolares de conteúdo

Movimento, Porto Alegre, v. 9, n. 1, p. 145-169, janeiro/abril de 2003 
fatual e informativo, deixando disciplinas de conteúdo mais atitudinal e procedimental em segundo plano. Isto é, a educação física está na escola, mas ninguém sabe bem o que fazer com ela do ponto de vista das políticas educativas e do projeto políticopedagógico da escola.

Nesse sentido, é importante recordar a análise da micropolítica da escola feita por Ball (1989). Segundo esse autor, a instituição escolar tende a valorizar mais as disciplinas acadêmicas do que as de caráter prático e expressivo, porque estas não oferecem o fundamento necessário para o progresso econômico e são difíceis de avaliar pela falta de medições objetivas que possam ser cobradas dos alunos nos exames. Além disso, os professores de disciplinas pouco convencionais não compartilham as metas normalmente estabelecidas pelo conjunto de professores da escola.

Ora, o ensino da educação física, concebido como o ensino da cultura corporal do movimento humano, pertencente à área de comunicação e expressão do currículo escolar, não tem um sentido prático imediato e tangível para o desenvolvimento econômico e social (possibilitar aos alunos o acesso qualificado ao mercado de trabalho). Portanto, é de supor-se que, no âmbito do sistema educativo, o trabalho do professorado de educação física careça de relevância no processo educativo como um todo. Segundo a participante Gloria:

O professor de educação física está marginalizado na escola pelo trabalho que faz.

Esse fato marca as diferenças entre o professorado de educação física e os professores de outras disciplinas.

De acordo com as falas dos participantes, o preconceito em relação ao professorado de educação física é duplo, porque acrescenta na desvalorização social generalizada do ensino público, a desvalorização específica da disciplina no âmago da escola. Carmem exemplifica essa questão dizendo:

Em minha escola, os alunos foram aprovados pelo Conselho Escolar, apesar da reprovação bem argumentada do professor de educação física.

O coletivo docente sustenta que são, especialmente, o governo e as políticas educativas públicas das diferentes instâncias da administração pública os máximos responsáveis pela sua desvalorização docente. Preocupam-se mais em controlar o trabalho dos professores do que oferecer condições para a produção do conhecimento na escola. Segundo Jorge:

Movimento, Porto Alegre, v. 9, n. 1, p. 145-169, janeiro/abril de 2003 
As políticas educativas do governo são sempre ideológicas, o que significa que os governantes as direcionam para onde querem, ainda que nem sempre tenhamo controle e as informações do que acontece nas escolas e na sala de aula...

Nesse espaço, o professorado realiza, segundo ele, ações de resistência. Porém, não se pode esquecer que nenhuma dessas duas ações de natureza política pode substituir, segundo Demo (1994), o papel do conhecimento, necessário tanto para planejar as finalidades educativas e sua administração, quanto para que a aula de educação física aconteça.

A crença da pouca valorização docente faz com que o professorado de educação física deposite pouca confiança nos governantes e nas administrações do sistema educativo. Pilar, como a maioria dos professores de educação física das escolas, sustenta que a desvalorização do professorado ganha visibilidade no aspecto econômico:

A maioria do professorado, enquanto esta dando aula está pensando no aluguel que tem que pagar no fim do mês. A questão é muito simples: a parte econômica está fazendo com que o professor deixe a convivência com os alunos. O baixo salário está fazendo com que o professor deixe de ensinar, deixe deler, de dedicar-se à educação. (...) Chego a conclusão que essa situação convém aos governos.

A crença da pouca valorização docente estimula o professorado a mover-se entre a rebelião e o consentimento. Essa é uma atitude que, muitas vezes, é por ele estimulada. Serve para justificar outras visões que esse professorado tem do seu trabalho e das estratégias de sobrevivência que leva à prática, na escola, com providências concretas. Por exemplo, o entendimento que o trabalho docente é o de um missionário do conhecimento, que sofre e faz seu trabalho com perseverança. Muitas vezes, essa idéia leva o professor a pensar que, ao ensinar, faz um favor aos alunos e à escola. Nuria pensa que

De alguma forma nós alimentamos os preconceitos que os outros têm a nosso respeito, essa diferença...tu acabas aceitando esta situação.

Outra conseqüência significativa desse pensamento é a que oferece ao professorado de educação física a justificativa necessária tanto para uma atividade docente descontextualizada e reprodutora, quanto para uma atividade transformadora e crítica, porque, faça o que fizer esse coletivo, aos olhos da escola e da sociedade está bem feito. Segundo o grupo de participantes deste estudo, os pais, mães e responsáveis só se preocupam com a educação física quando seus filhos têm problemas de saúde ou quando chegam em casa com algum dano físico. Para Francisco,

Movimento, Porto Alegre, v. 9, n. 1, p. 145-169, janeiro/abril de 2003 
o professor de educação física pode fazer o que quiser porque ninguém se preocupa com a qualidade de seu trabalho, o que interessa é que cumpra as obrigações administrativas. Os planos de ensino, a proposta pedagógica que fazemos, ficam nos arquivos, penso que ninguém as lê, ninguém conhece o que fazemos. O professor que entrega a avaliação no prazo é um professor nota dez.

Esse desconhecimento permite ao coletivo explorar e construir com seus alunos uma crítica ao contexto social, independente dos aspectos relacionados ao conteúdo da disciplina. Jorge afirma que

...independente dos planos, meu objetivo é trabalhar para formar cidadãos que pensem, que questionemoque aí está.

O ícone da pouca valorização docente materializa um pensamento divergente, o que possibilita ao professorado de educação física construir diferentes visões da escola pública. Houve várias definições, contudo as mais significativas pela sua alteridade foram: ..um lugar de não fazer nada..., ...um lugar de luta política..., ...uma fábrica de talentos... e ...um lugar de ensino de valores humanos....

Para Nuria, essas diferentes visões da escola pública estão relacionadas com a execução das políticas públicas de educação. Freqüentemente, há coincidência ou contradição com o pensamento do professor.

A crença da pouca valorização docente também interfere na visão que o professorado de educação física tem dos alunos. Entre elas sublinho: ...um cliente que recebe um serviço público..., ...alguém que gosta de trabalhar e ser avaliado por isso..., ...um adolescente preguiçoso..., ... a razão de ser de todo o sistema educativo... e ...um futuro agente de transformação social.... Contudo, todos estão de acordo com a afirmação de Pilar:

Oaluno nãoé uma escultura que tu pões num pedestal e trabalhas como queres.

Oalunoéum todo que pensa, conhece e sente.

A desvalorização docente estimula, também, o professorado de educação física a abandonar algumas atividades comuns a todos os docentes de uma escola, como formalizar seu planejamento do ensino e comparecer a reuniões gerais da escola. Além disso, sob essas circunstâncias administram seu tempo escolar de forma autônoma, fato que gera críticas do coletivo docente da escola quanto a possíveis privilégios desse professorado na escola e a pouca seriedade da disciplina.

Movimento, Porto Alegre, v. 9, n. 1, p. 145-169, janeiro/abril de 2003 
Como se vê, através do ícone sucateamento da escola pública, o professorado de educação física propõe respostas utilitárias às interferências externas que incidem sobre seu trabalho docente. Entendo que é uma linha de respostas que se caracteriza, com freqüência, como redefinição estratégica e, às vezes, como obediência estratégica. A redefinição acontece quando o coletivo reage e denuncia sua desvalorização docente no interior da escola, isto é, quando assume uma atitude de compromisso docente ante o sistema educativo. Também ganha visibilidade quando o coletivo propõe um discurso que reivindica às demais parcelas da comunidade escolar uma visão conseqüente sobre seu trabalho. A submissão ou obediência estratégica se materializa quando o professorado de educação física aceita, sem reagir, a desvalorização de seu trabalho docente, e estimula a comunidade escolar a atribuir pouco valor docente ao seu trabalho na escola.

\section{A crença do professor diferente Ícone: companheirismo}

A crença de que os professores de educação física são diferentes dos demais professores está relacionada à especificidade de seu trabalho na escola, ao conhecimento que o coletivo compartilha e aos modelos de intervenção pedagógica. Destaco que tal crença provém da síntese de como ele vê a si mesmo, traduzido por uma imagem positiva, e como imagina que as outras parcelas da comunidade escolar o vêem, representado na forma de como a escola atribui qualidade ao seu trabalho. Essa crença está, sobretudo, vinculada à imagem pública que o coletivo constrói e revela no cotidiano da escola e fora dela.

Essa crença oferece ao professorado de educação física outra oportunidade de manifestar seu pensamento divergente e concretizar outras estratégias de sobrevivência. Ainda que manifeste publicamente que é um professor igual aos demais, porque ocupa um posto de trabalho com características e finalidades idênticas a dos professores de outras disciplinas, acredita que é um professor diferente porque tem boa comunicação com os alunos e porque trabalha com procedimentos corporais e atitudes pessoais e sociais. Esse é um dos argumentos que o faz acreditar que o coletivo de professores da escola tem pouca compreensão de seu trabalho.

Essa crença dá sentido e justifica os diferentes papéis que o professorado de educação física assume ante o aluno. Destaco o

Movimento, Porto Alegre, v. 9, n. 1, p. 145-169, janeiro/abril de 2003 
papel de companheiro do aluno, pois este é mais visível nas atividades escolares. Misto de pai e amigo, Xavier sintetiza esta visão:

Sou para os meus alunos, o professor que gostaria para meus filhos. Então o professor de educação física é aquele professor que sabe o que está fazendo, queé responsável, queé amigo, que é um companheiro dos alunos, mas que também está preocupado com sua educação.

Na visão do professorado de educação física, os demais professores da escola não os reconhecem pelo conhecimento que acumulam, mas por uma série de formalismos externos e pensam que a finalidade de seu trabalho é ocupar o aluno, sem interessar como. Para Paula,

O bom professor para esta escola é assiduo e pontual. Não deixa os alunos vagando pela escola sem atividade. Para a direção, se o professor mantém os alunos ocupados, não importa o que está fazendo com os alunos...Se mantém os alunos ocupados, se entrega seus planos e a avaliação nos prazos corretos, é um bom professor. Éisso quenecessita.

Nesse sentido, quando há necessidade de alguma atividade escolar compensatória no âmbito da escola, ou os professores têm outras atividades a realizar, ou um problema para resolver (por exemplo, reuniões gerais da escola), a direção e a supervisão colocam os alunos sob os cuidados dos professores de educação física para que eles fiquem ocupados, situação aceita pelo coletivo docente, que também a utiliza como meio para barganhar seus interesses. A queixa é que os alunos são largados para o professor de educação física, não para uma atividade pedagogicamente conseqüente, mas para que fiquem ocupados.

Outra visão que está associada ao símbolo companheirismo é a idéia de que o professor de educação física é aquele tipo disposto, alegre, prático e que sabe fazer bem. Paula considera que para o professor de educação física o bom é fazer, ele faz, não gosta de planejar. Ele aproveita a oportunidade e os meios disponíveis para fazer seu trabalho.

Essas atitudes também divergem do formalismo e dos rituais escolares compartilhados pela maioria dos professores e alunos da escola, fato que também contribui para que sejam incompreendidos pela comunidade escolar. Para Xavier, é a relação que o professor tem com seu próprio corpo que o faz mais alegre e adotar posturas pouco ortodoxas:

Esta coisa de tocar o outro, de dar uma abraço, de rir, de ter uma postura irreverente, de tratar o aluno sem formalismo. Penso que por isso é mal compreendido (...) Para fazer isso ele tem que estar muito seguro do seu trabalho e tem quegostar das pessoas.

Movimento, Porto Alegre, v. 9, n. 1, p. 145-169, janeiro/abril de 2003 
A crença de que a disciplina tem uma finalidade educativa diferente

Ícone: convivência

A crença de que a educação física tem uma finalidade educativa diferente provém da incerteza que toma conta do professorado de educação física, no âmbito da prática docente, na hora de definir os objetivos a alcançar na sua ação pedagógica e programar os conteúdos de suas aulas. Por outro lado, a crença também ganha corpo na compreensão limitada que o corpo docente da escola tem do tipo de conhecimento que o professorado adota como conteúdo de ensino nas aulas de educação física. Recentes trabalhos, entre os quais o do Coletivo de Autores (1992) e de Kunz (1994) são tentativas de esclarecer essa questão: o que ensinar nas aulas de educação física?

Para Kunz (1994), o processo de ensino da educação física deve oferecer ao estudante a oportunidade de desenvolver competências técnicas no âmbito da disciplina - as técnicas corporais - e as competências sociais e comunicativas. Portanto, conforme os argumentos do Coletivo de Autores (1992),

A Educação física é uma disciplina que trata, pedagogicamente, na escola, do conhecimento de uma área denominada aqui cultura corporal. Ela será configurada com temas ou formas de atividades, particularmente corporais, como as nomeadas anteriormente: jogo, esporte, ginástica, dança ou outras, que constituirão seu conteúdo. O estudo desse conhecimento visa aprender a expressão corporal como linguagem. (p.61-2)

De todas as formas, mesmo com importantes avanços teóricos, parece que, no âmbito da escola, o professorado de educação física enfrenta a seguinte situação: enquanto a programação do ensino escolar predominante nas escolas públicas de Porto Alegre trata da transmissão do conteúdo fatual, conceitual e informativo acumulado, na educação física eles trabalham com ênfase em conteúdos mais procedimentais e atitudinais. Essa situação favorece o surgimento de certa incredulidade ao trabalho do professor de educação física e contribui para que o coletivo represente a si mesmo como diferente dos demais professores. $\mathrm{O}$ coletivo se percebe diferente porque pensa que, enquanto as demais disciplinas do currículo escolar centram suas finalidades educativas nos aspectos cognitivos, culturais e intelectuais do estudante, a principal finalidade da educação física na escola está em outro plano.

Movimento, Porto Alegre, v. 9, n. 1, p. 145-169, janeiro/abril de 2003 
Os participantes deste estudo consideram que a finalidade educativa das aulas de educação física está centrada na contribuição à saúde física do aluno; na forte intervenção no âmbito de suas atitudes, no interior da escola (essas ações repercutam na atividade do aluno no contexto social mais amplo), e também no caráter compensatório ao trabalho intelectual e abstrato que a cultura escolar impõe ao estudante. O conteúdo específico (os esportes, a ginástica, a dança e outros), em sua opinião, não ocupa um lugar destacado, e sua transmissão é circunstancial. De forma minoritária, a disciplina é pensada como possibilidade de contribuição para a produção de conhecimento por parte do estudante. Esta é a crítica de Helena:

...o que eles dizem que é educação física, queéo que estáacontecendo agora, alino pátio, nãoéeducação física, éuma hora livre, éuma hora derecreio. Oferecem umas cordas, umas bolas e deixam que os alunos corram soltos. Inclusive os pais pensam queéeducação fisisica, porqueninguém se deu conta queeducaçãofísica éoutra coisa.

Parece que, nessa situação de contraste entre o pensamento do professorado de educação física e o do corpo docente da escola, não está se considerando o conceito de conteúdo de ensino de forma ampla. Antes, quando se falava de conteúdo de ensino se pensava na transmissão da informação, dos conceitos, e dos fatos. Atualmente, cada vez mais se entende que, junto à compreensão dos conceitos, arrolam-se como conteúdos de ensino os procedimentos, as atitudes e as formas de estar e conviver com a diversidade social e a pluralidade de pensamentos. É um outro tipo de trabalho que vai além do que aprender, mas que considera o como aprender um conteúdo do currículo escolar tão importante quanto os que tradicionalmente se considerava.

Ana considera que a finalidade da educação física na escola transcende a questão formal do conteúdo e ensina uma forma alternativa de viver, ensina o aluno a cuidar melhor de seu corpo.

João pensa ao contrário: para ele a educação física, em suas atividades esportivas mostra ao aluno uma faceta da sociedade que a escola pública procura ocultar. Justifica sua posição dizendo que a escola pública, no contexto brasileiro, tenta adaptar o aluno ao seu lugar social, ao contrário da educação física que, ao promover a competição, conduz e estimula o aluno a lutar por uma perspectiva de vida melhor, pois essas são as normas da sociedade. Outros colegas seus discordam dessa posição, considerando-a conservadora, dado que não incita a transformações, nem educativas, nem sociais. É uma posição que vê somente o lado pragmático da questão em que se insere a competição escolar.

Movimento, Porto Alegre, v. 9, n. 1, p. 145-169, janeiro/abril de 2003 
Nuria enfatiza a questão da sociabilidade e o caráter compensatório da educação física ao bombardeio que os alunos recebem nas outras aulas. Por outro lado, Silvia considera que a educação física contribui para o ensino interdisciplinar. Para José, a educação física na escola contribui fundamentalmente para a convivência. E afirma:

Penso que essa é a missão da educação física. Um jogo, uma partida de futebol, em si, não quer dizer nada, de basquetebol não quer dizer nada. Ser um ótimo atleta também não quer dizer nada. Mas se tu consegue que a turma ou o grupo inteiro consiga conviver entre si, jogar sem que haja uma agressão, sem conflitos, sem que os alunos deixem as aulas descontentes, que não aconteça disputas violentas, então eu penso que a educação física alcançou seus objetivos totalmente.

Rosa pensa que:

É importante que preparemos os alunos para participar. Ele deveria conhecer um pouco de tudo, para que em momentos de lazer possa jogar, possa participar livremente, sem medos, que tenha segurança com estas coisas eque possa fazê-las fora da escola. (...) E estas situaçôes, estas coisas, aplicá-las na vida, não só no aspecto do jogo, senão o de participar fora da escola em grupos, integrar-se neles. Pode entrar e sair de um grupo, aceitando as diferenças. Istoé muito importante.

Na opinião de Francisco, a educação física auxilia o aluno para que tenha um tempo livre mais são. Glória afirma que, através da educação física, detecta o aluno com problemas de comportamento e o ajuda a superá-los. Para ela,

...o seu trabalho na educação física tem que romper com a rotina da escola e das aulas. O aluno está dentro de sala de aula e vem para o pátio para recrear-se e aprender. Não é só recreio, vem aprender uma atividade que Ihe ajuda no diadia. Detecto o aluno tenso, ansioso e Ihe ensino a controlar isso. Ajudo-lhe a encarar melhor essa situação. Ajudo o aluno a conhecer-se e saber queécapaz de fazer certas coisas. Então é uma lição de vida que a educação lhe dá. Esta é minha preocupação, transmitir-lhe isto. Que decida por si mesmo. No esporte coletivo vem a bola e ele não sabe o que fazer, chega até ela e desiste. Simbolicamente, é uma situação de vida. Tem que enfrentá-la e chutar ou mandar a bola para outro lado. Istoé, transpor uma barreira em sua vida. Esse trabalho éque nos gratifica.

Pode-se pensar que, mesmo que alguém considere que nas disciplinas de matiz mais intelectual também existam espaços para trabalhar essas características apontadas por Glória e seus colegas como pertinentes à educação física, elas servem para diferenciá-los e desenhar um modelo amplo de professor de educação física nas escolas públicas, pois são singularidades do estudante que têm forte visibilidade nas aulas de educação física escolar.

Movimento, Porto Alegre, v. 9, n. 1, p. 145-169, janeiro/abril de 2003 


\section{A crença de um modelo de professor para a escola pública \\ Ícone: prático-reflexivo}

O professorado de educação física crê que não é qualquer tipo de professor de educação física que tem condições adequadas para realizar um trabalho conseqüente em um contexto/ ambiente com características tão complexas como o das escolas públicas de Porto Alegre. Entendem que para trabalhar em um ambiente onde circulam e competem concepções ideológicas tão diversas e antagônicas, onde coabitam e atuam uma multiplicidade de grupos de poder, e que acolhe alunos de segmentos culturais tão diferentes, é necessário ter qualidades especiais. Como sublinha a metáfora de Felipe, é necessário ser um Super-Homem. Por outro lado, Jorge destaca que para fazer esse trabalho implica esquecer alguns aspectos da formação inicial e aprender a trabalhar em outra perspectiva, a perspectiva humanista, e assim se expressa:

Penso que a finalidade da educação física no contex to escolar é formar agentes de transformação social. Antes pensava que era formar atletas. Agora utilizo a educação fisica como um meio de questionamento social e de formação corporal. Mostro-lhes para que serve o corpo. Comoéutilizado o corpona sociedade equem se serve dele? A partir daí vou mostrando as influências que uma boa formação tem para transformar a sociedade. Tenho trezentos e cinqüenta alunos por semana. Se consigo que a metade deles tenha uma formação diferente, veja a sociedade de forma mais humana e mais digna; Se consigo com a metade deles uma resposta favorável para mudara sociedade, terei tido êxito no meu trabalho, independente se eles amam ou não o esporte, se eles gostam ou não da atividade física. Estaéminha preocupação.

É nesse sentido que o modelo de professor de educação física para o coletivo docente se aproxima da vertente humanista, posição algumas vezes criticada dado seu caráter idealista e ingênuo em relação à realidade social e aos conteúdos tradicionalmente programados nas aulas de educação física. A essa definição, os professores dizem que é preciso acrescentar o conhecimento de determinados conteúdos específicos que lhes proporcionará a mediação com o aluno e seu conhecimento da realidade social. João, em suas aulas, assume uma postura humanista que tenta ser esclarecedora quando diz:

Procuro dizer-lhes que a realidade social não é recreação. Que a vida fora das aulas é competição, ainda que eu questione a competição.

Considerando-se que na educação física escolar, especificamente na escola pública, os planos de estudos são pouco

Movimento, Porto Alegre, v. 9, n. 1, p. 145-169, janeiro/abril de 2003 
estruturados e normatizados, qualquer orientação pedagógica que um professor adote servirá para estruturars seu ensino, seja na perspectiva do técnico desportivo, do recreacionista, do fisicultor ou de um pedagogo. Segundo José:

Deveria haver uma forma de aula que se pudesse dar uma atenção melhor ao aluno, em termos de fazer uma educação física mais aplicada em modalidades esportivas como voleibol, basquetebol ou atletismo, onde os alunos sairiam da escola com uma base para ser aprimorado fora da escola em uma esfera superior.

Essa posição também é suscetível de crítica, considerandose a história dessa disciplina que, em certa época, instrumentalizada pelo desporto, incentivou o professorado de educação física a formar atletas nas aulas de educação física, esquecendose dos aspectos gerais da educação escolar e de uma postura mais crítica em relação ao contexto sociocultural.

Nessa discussão não há consenso. Contudo, o acordo possível sobre um modelo adequado de professor de educação física para a escola pública é de que esse docente faça o possível para que o aluno ultrapasse a especificidade da disciplina em direção ao universo educacional e social. Que ele se atualize para esse trabalho e aplique suas experiências na vida cotidiana das aulas. O professorado de educação física deixa claro que o modelo de professor adequado para a escola pública, além desse caráter reflexivo, é aquele que serve de exemplo para seus alunos. Para Xavier,

Oprofessor de educação física tem que saber fazer, e tem que sero exemplo em suas atitudes. Não convence a ninguém fazer discurso sobre a importância da atividade física e não ter cuidado consigo mesmo nesse aspecto, que não faço aquilo que diz. Penso que o professor tem que ser o exemplo. Se vai trabalhar com esportes, claro que ele não será o máximo em esportes, mas tem que saber alguma coisa para mostrar para os alunos. Isso é importante, estimula mais o aluno.

A partir das declarações anteriores e a figura do exemplo (do que mostra como se faz) que acima aparece, pode-se intuir que, para o professorado de educação física da escola pública, o modelo adequado de professor para trabalhar nesse ambiente é um trabalhador que ao seu caráter reflexivo/humanista acrescenta a habilidade específica de saber fazer o que ensina, de conhecer e executar as diferentes técnicas corporais que ensina. Em outras palavras, um humanista com conhecimento específico da disciplina. Uma mescla de discóbulo e pensador, ${ }^{9}$ um prático-reflexivo (Schön, 1992).

9 Refiro-me às esculturas do Discóbulo de Mirón, e o Pensador de Rodin, que como modelos artísticos representam o homem, em movimento e em pensamento profundo, respectivamente.

Movimento, Porto Alegre, v. 9, n. 1, p. 145-169, janeiro/abril de 2003 


\section{As estratégias de sobrevivência: implicações no conhecimento dos professores de educação física e em sua prática pedagógica}

Creio que as crenças do professorado de educação física (a crença do baixo valor docente; a crença de uma especificidade diferenciada da sua disciplina, a crença de ser um professor diferente dos demais e a crença de que há um modelo adequado de professor para trabalhar na escola pública) são elementos decisivos na configuração da cultura docente desse coletivo de professores e, como sublinhei, tem implicações decisivas em sua ação no dia-a-dia da escola.

Assim, a partir do enfoque etnográfico do pensamento, idéia proposta por Geertz (1996), considero essas crenças um artefato cultural de um coletivo, que se organiza a partir do mundo de significados que ele mesmo constrói socialmente. Antes de um ato individual que se produz na cabeça de alguém, o pensamento é essencialmente social, em suas origens, em suas funções, formas e aplicações. É uma atividade, sobretudo, pública. Para Geertz (1996, p. 82),

...implica que o pensar humano é primeiramente um ato público desenvolvido com referência aos materiais objetivos da cultura comum eque secundariamente é uma questão íntima, privada. Tanto o pensamento dirigido, como a expressão dos sentimentos e a integração deles em motivos, os processos mentais do homem se verificam, certamente, no escritório do estudioso ou no campo de futebol, no estúdio ou no assento do caminhoneiro, no estrado, no tabuleiro de xadrez ou no gabinete dojuiz.

Considero, além disso, que as crenças do professorado de educação física da escola pública articulam-se com os demais elementos constitutivos de sua cultura docente (experiência, prática, conhecimento e formação). Destaco como enlaces muito significativos para compreender o ambiente escolar os que se estabelecem com o conhecimento e a prática da sala de aula.

No âmbito do conhecimento, as estratégias de sobrevivência mostram como esse coletivo docente ultrapassa o conteúdo específico da matéria de ensino e acessa a outros espaços de saber da escola a partir da redefinição das finalidades e dos conteúdos da disciplina. As estratégias dão visibilidade à idéia de que o coletivo desenvolve, sobretudo, um conhecimento

Movimento, Porto Alegre, v. 9, n. 1, p. 145-169, janeiro/abril de 2003 
pedagógico de natureza prática no trato com o aluno. Que desenvolve um conhecimento de como movimentar-se na escola, de como integrar-se com o aluno e com as demais parcelas da comunidade educativa, e como viabilizar o ensino dentro das condições disponíveis. Para o desenvolvimento desse tipo de conhecimento é importante considerar os diferentes significados que o professorado dá à disciplina no currículo escolar.

No âmbito da prática docente, as crenças ainda têm maior impacto como estratégias de sobrevivência porque minimizam os efeitos da subordinação pedagógica de sua cultura docente particular à cultura escolar tradicional. Cabe dizer que o professorado de educação física redefine os princípios da cultura escolar de acordo com seus interesses pessoais e docentes, programando suas classes e definindo seu conteúdo.

Em conseqüência dessa redefinição, essas crenças permitem ao coletivo possibilidades de movimentar-se criticamente no interior da cultura pedagógica, sem comprometer-se demasiadamente com ela, garantindo, assim, por um lado, a ineficácia dos meios de controle da administração do sistema educativo sobre seu trabalho, mas, por outro, recebendo a incredulidade sobre sua contribuição educativa.

Dando ênfase às suas crenças, o professorado de educação física garante, na escola pública, uma autonomia relativa, e também amplos espaços de negociação política no interior da escola pública. Na minha perspectiva, essa autonomia relativa é, talvez, um dos traços mais característicos da cultura docente dos professores de educação física das escolas públicas de Porto Alegre, e um modo de atuar que mais contrasta com os rituais que se realizam diariamente na cultura da escola.

As crenças docentes se constituem em um elemento, uma parte do meu interesse de estudo - a cultura docente dos professores de educação física. Neste trabalho, através da interpretação de determinadas singularidades sobre o pensamento desses professores, busquei ampliar a compreensão do fenômeno estudado, consultando a bibliografia e refletindo sobre o discurso dos professores colaboradores. Segui, assim, os conselhos de Geertz (1996): o caminho para o geral, através da simplicidade reveladora da ciência, passa pelo interesse no particular, no concreto e no circunstancial.

Movimento, Porto Alegre, v. 9, n. 1, p. 145-169, janeiro/abril de 2003 
As crenças docentes se revelam elementos expressivos da cultura docente dos professores. Resultantes da relação dialética com a ação desses professores nas escolas, elas revelam a essência de seu pensamento sobre seu trabalho na escola pública e atuam como estratégias de sobrevivência no interior da escola. Seu caráter público e social expressa os valores e princípios que orientam sua ação na escola. Essas crenças oferecem aos professores a possibilidade de atuar criticamente no interior da cultura pedagógica, redefinir os princípios dessa cultura a seu favor e minimizar os instrumentos de controle do sistema educativo sobre seu trabalho. A divulgação insistente de suas crenças, feitas pelos próprios, são decisivas para garantir-lhes ampla autonomia relativa no exercício do trabalho docente. Facilitar que os professores de educação física reflitam sobre suas crenças docentes é um bom caminho para viabilizar um projeto conseqüente de formação profissional e discutir sua contribuição educativa.

\section{Beliefs of physical education teaching staff of public schools in Porto Alegre, Brazil}

Abstract : The present study examined the teaching beliefs of 20 physical education teachers of public schools in Porto Alegre, Brazil. The nature of the present study was qualitative and, predominantly, etnographic. The author observed teachers in their day-to-day at school, carried out semistructured interviews, and registered his impressions and significant events on a field diary. Teaching beliefs appeared as significant elements of the teaching culture of physical education teachers. Teaching beliefs are a window to the thoughts of teachers on their role in school, appear as strategies for survival in the school environment, and enable teachers to extend their relative autonomy in the exercise of their work. Helping physical education teachers reflect on their teaching beliefs may contribute to the discussion on their academic education.

Keywords: Teacher's Work; Training of Teachers; Work of the Teacher of Physical Education. 
Creencias del profesorado de Educación Física de las escuelas públicas de Porto Alegre - RS/Brasil

Resumen: El estudio examina las creencias de docentes de 20 Profesores de Educación Física de las escuelas públicas de Porto Alegre - RS, Brasil. Las decisiones metodológicas fueron de naturaleza, predominantemente, etnográfica. Hice observaciones de estos profesores en el cotidiano de las escuelas, entrevista semi-estructuradas e he registrado mis impresiones y eventos significativos en un diario de campo. Las creencias docentes han mostrado elementos expresivos de la cultura docente de los profesores de educación física. Ellas dan visibilidad al pensamiento de los docentes sobre su acción en la escuela, se muestran como estrategias para sobrevivir en el ambiente escolar e ofrecen a los profesores la posibilidad de ampliar su autonomía relativa en ejercicio de su trabajo. Facilitar que los profesores de educación física hagan reflexiones sobre sus creencias docentes puede contribuir para la discusión de su formación profesional.

Palabras claves: Trabajo Docente; Formación de Profesores; Trabajo del Profesor de Educación Física.

\section{Referências}

AGUIRRE Baztán, Ángel (1995) Etongrafía. En: Aguirre Baztán, Ángel (Ed.) Etnografía: Metodología cualitativa en la investigación social. pp. 03-19. Barcelona: Marcombo.

BALL, Stephen J. (1989). La micropolítica de la escuela: Hacia uma teoria de la organización escolar. Barcelona. Paidés.

CALDERHEAD, James (1988). Conceptualización e investigación del conocimiento profesional de los professores. In. Villar Angulo, Luis Miguel. Conocimientos, creencias y teorías de los profesores. Implicaciones para el curriculum y la formación del professorado. Pp. 21-37. Alcoy: Marfil.

CLARK, Christopher M. y Peterson, Penelope L. (1990) Procesos de pensamiento de los docentes. In: Wittrock, Merlin C. La Investigación en la Enseñanza III. Professores e Alunos. Pp. 444-531. Barcelona: Paidós Educador

CONTRERAS DOMINGO. Jose (1985). ¿EI pensamiento o el conocimiento del profesor? Una crítica a los postulados de las investigaciones sobre el pensamiento del profesor y sus implicaciones para la formación del profesor. In: Revista de Educación n²77. Pp. 05-26. Madrid: MEC.

DEMO, Pedro (1994). Pesquisa e construção de conhecimento. Metodologia da pesquisa no caminho de Habermas. Rio de Janeiro: Tempo Brasileiro.

Movimento, Porto Alegre, v. 9, n. 1, p. 145-169, janeiro/abril de 2003 
FREIRE, Paulo (1979). Pedagogía del Oprimido. Trad. Jorge Mellado. 21ª ed. Madrid: Siglo XXI.

FREIRE, Paulo (1992). Pedagogia Da Esperança: Um Reencontro com a Pedagogia do Oprimido. São Paulo: Paz E Terra.

GEERTZ, Clifford (1994). Conocimiento Local: ensayos sobre la interpretación de las culturas. Barcelona: Paidós.

GEERTZ, Clifford (1996). La interpretación de las culturas.7ª ed. Barcelona: Gedisa.

GUERRERO Lopéz, José Francisco (1993). El laboratorio mental del profesor: Los procesos cognitivos que reorganizan la conduta docente. In: Revista de Educación nº 300. pp. 157-172. Madrid: MEC.

LACEY, C. (1977) The socialization of teachers. Londres: Methuen.

MARCELO García, Carlos (1987). El pensamiento del professor. Barcelona: CEAC.

MARCELO García, Javier (1992). Teorias implícitas del profesorado. Um puente entre la cultura y la práctica de la enseñanza. In: Estebaranz García, A y Sánches García, V. (Eds.) Pensamiento de Profesores y Desarrollo Profesional. pp. 09-21. Sevilla: Universidad de Sevilla.

SCHÖN, D. (1992) La formación de profesionales reflexivos. Madrid: Paidós/ MEC. [Edición original en inglés, Educating the reflexive practioner, Londres: Jossey-Bass.]

WOODS, Peter (1989). La escuela por dentro. La etnografia de la investigación educativa. Barcelona: Paidós / MEC.

ZEICHNER, Kenneth M. (1985). Dialéctica de la socialización del professor. In: Revista de Educación no 277. pp. 99-127. Madrid: Mec

ZEICHNER, Kenneth M. (1992).Formación reflexiva del profesorado desde una perspectiva crítica. In: Estebaranz García, A y Sánches García, V. (Eds.) Pensamiento de Profesores y Desarrollo Profesional. pp. 309-325. Sevilla: Universidad de Sevilla

Vicente Molina Neto Felizardo, 750

Escola de Educação Física 90690-200 - Porto Alegre/RS vicente.neto@ufrgs.br

Movimento, Porto Alegre, v. 9, n. 1, p. 145-169, janeiro/abril de 2003 